\title{
A Parallel Group Randomised Control Study to Investigate the Efficacy of Weekly Motivational Text Messages on Adherence among Clients on Anti- Retroviral Therapy- Kadoma Mobile Phone Study (KAMPS) 2016-17
}

\author{
Article by D. Chirundu ${ }^{1}$, P.N. Magande ${ }^{2}$, Adrian Musiya ${ }^{3}$, Sikhanyisiwe Moyo ${ }^{4}$, T. Mduluza \\ ${ }_{1,4}^{1, K a d o m a}$ City Health Department, Zimbabwe \\ ${ }^{2,3}$ University of Zimbabwe Department of Community Medicine, Zimbabwe \\ ${ }^{5}$ University of Zimbabwe Department of Biochemistry, Zimbabwe \\ Email:dchirundu@me.com ${ }^{1}$,pmagande@gmail.com ${ }^{2}$,drnyahaadrianmusiya@gmail.com ${ }^{3}$, \\ skhaemoyo@gmail.com ${ }^{4}$,tmduluza@medic.ac.zw
}

\begin{abstract}
Background: Anti-retroviral therapy was introduced in 1997 to manage people living with the Human Immune-deficiency virus (HIV). The success of treatment is dependent optimal levels of $95 \%$ or more adherence. A 2015 study conducted at the Rimuka Integrated HIV and TB Centre, revealed a suboptimal adherence rate of $87 \%$ by self-report and $65 \%$ by pill counts. We set out to investigate the efficacy of cell phone short message service on adherence among clients on ART at the center.

Methodology: KAMPS was a parallel design randomized controlled trial of HIV clients receiving ART at Kadoma (Zimbabwe). Respondents were randomised 1:1. Respondents in the intervention group received a weekly motivational SMS in addition to standard HIV care whilst those in the nonintervention arm received standard care alone. The primary outcome was adherence measured using a composite scale. Secondary outcomes were weight, CD4+; and, viral load, measured at baseline and 26 weeks. The primary analysis was by intention to treat. The trial was registered PACT20161001858240.

Results: Of the 552 assessed respondents, 470 were eligible and were randomized into the study. However, analysis was done for 449 respondents. At 26 weeks, 180 (76.9\%) respondents in the intervention group were considered adherent compared to 127(59\%) in the non-intervention group $(p=0.65)$. The mean CD4+ cell count at six months was 554 cells $\mathrm{mm}^{-3}$ among those in the nonintervention group compared to 619 cells per $\mathrm{mm}^{-3}$ among those in the intervention group. Mean viral

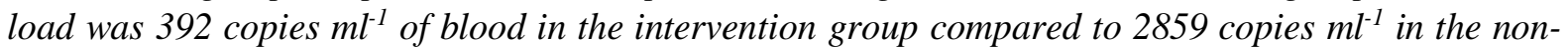
intervention arm. Among those in the intervention group 140(60\%) had viral suppression compared to $93(43 \%)$ in the non-intervention arm.

Conclusion: We conclude that weekly motivational short message influenced adherence and ultimately CD4+ cell count, viral loads and viral suppression.
\end{abstract}

Keywords: Adherence, ART, HIV, Kadoma, mHealth, Zimbabwe.

\section{Introduction}

Antiretroviral (ARV) medications are treatments for people living with the Human Immunodeficiency Virus (HIV) whose aim is to drive viral load below the current detection limit. ARV medications were not available for treatment of HIV/AIDS complications prior to approval by Food and Drug Administration 1986. They became publicly available in 1997 after introduction of two drugs Zidovudine and Lamivudine (Diederich W.E. \& Stenber H. 2015).

Successful treatment with ARVs reduces the destruction of cluster of differentiation 4+ (CD4+) cells, immune suppression, HIV transmission and, slows disease progression. This can be seen in rising CD4+ cell counts, undetectable viral loads and clinical improvement. As viral load assays are expensive in resource limited settings, CD4+ counts and clinical physical examination are the main tools for monitoring treatment outcomes (Hammer S., et.al. 1997).

Unfortunately, there are several problems associated with anti-retroviral therapy (ART). These include the development of drug resistance, the difficulties of maintaining compliance, long-term adherence and drug-related toxicities. All these may lead to virological failure. Virological failure in 
turn leads to immunological failure, clinical progression of HIV and ultimately death (Mocroft A, et.al. and Department of Health and Human Services 2017). Adherence to ART is, critical to the survival of HIV infected individuals (The PLATO Collaboration 2004). The optimal level of adherence required for ARVs medication to work effectively is 95\%. (Paterson David L., et.al. and Reiter G., et.al. 2000). Anything less than this optimal level of compliance leads to rapid development of viral resistance and hence to treatment failure. According to Lima et. al. (2000), for a five percent reduction in adherence, there is a fivefold increase in virological indices. Therefore, successful HIV treatment requires strict adherence to medication.

Adherence is defined as: 'The extent to which the patient's behaviour matches agreed recommendations from the prescriber.' (Horne R, et.al. 2006). In HIV infection, adherence to ARV has been strongly correlated with viral suppression and results in improved clinical presentation and health outcomes (Bangsberg D. 2006). Non-adherence is associated with development of HIV drug resistance whose risk is highest in individuals with incomplete adherence (e.g. 80\%-90\%). The link between adherence and development of resistance depends on potency and pharmacokinetics of the regimen combinations. The phenomenon of non- adherence has been linked to limited future HIV treatment options and combinations causing HIV drug resistance and increases risk of HIV transmission (Mills Edward J, et.al.2006 and Palella FJ. et.al 1998).

Although adherence has emerged as a major determinant of the success associated with ART, it is not the only determinant of ART success or failure (Braitstein P, 2006). Other determinants of ART failure or success include genetic differences in drug metabolism, severe baseline immune suppression, prior drug resistance and concurrent opportunistic infection (Reiter G., et.al. 2000). Adherence to ART however, remains, one of the few alterable factors determining outcomes for patients with HIV. ART adherence is the second strongest predictor of progression to AIDS and deaths. The first predictor being CD4+ count (Ickovics J.R, \& Meade C.S. 2002).

It is imperative that patients on ART be supported to ensure treatment success. Of late mobile health technology ( $m$ Health) has emerged as a tool to support health care delivery including improving adherence (Ickovics JR, \& Meade CS (2002) and Labrique Alain B, et.al. 2013). Several studies, among them clinical trials have been conducted to evaluate the utility of $m$ Health and the use of reminders, to promote adherence to ART (Mbuagbaw L et.al. (2011); Pop-Eleches C. et.al. (2011); Kelly J. et. al.; Lester R. et.al. (2010); Dongsheng H., et.al. (2013); da Costa, et. al. (2012) and Hardy et. al. (2011). However, there are still many gaps and the quality of some of the trials leaves a lot to be desired.

A 2015 study on adherence to ART among clients seeking HIV care at Rimuka Integrated HIV and TB Centre (RIHTC) revealed an adherence rate of $87 \%$. This was based on self-reports. However, pill counts at the health center among a subset of respondents, revealed that the adherence was $65 \%$ (Muringazuva $\mathrm{C}$ et.al. 2015). This is a cause of concern since ART adherence should be above $95 \%$ to have virological or public health impacts (Paterson David L., et.al. and Reiter G., et.al. 2000). It is against this background that we set out to investigate novel ways to improve adherence among clients on ART so that the benefits of treatment are maximized.

We hypothesized that clients on ART who receive a weekly motivational SMS in addition to standard HIV care at RIHTC are more likely to be adherent to ART than those receiving standard HIV care alone. We set out to investigate the efficacy of cellphone short message reminders on adherence to antiretroviral therapy among clients seeking HIV care at the Centre.

\section{Methods}

We report here an overview of the methods. Details of the study protocol are published elsewhere (Chirundu, D. et.al. 2017).

\section{Study design}

This was a parallel design randomized controlled trial (RCT) to investigate the efficacy of weekly motivational short message service (SMS) on adherence to ART. 


\section{Trial setting}

Rimuka Integrated HIV and TB Centre (RIHTC) was the trial setting. The facility is operated by Kadoma City Health department in Zimbabwe. Other facilities providing health care in the city include six municipal clinics, eight private practitioners, two private hospitals and one government referral centre. All these except one offer various HIV services. The HIV prevalence in the town was estimated to be $14 \%$ in 2016 . The total number of clients on ART who were being managed by Kadoma City Health was 8225 in 2016.

\section{Study population and study unit}

The study population were HIV clients enrolled for care at RIHTC. The study unit was an individual client on the RIHTC register.

\section{Eligibility}

We included in the study any person, registered on the RIHTC ART register, who has been on ART for at least 4 weeks, owned a cell phone, and, was willing to receive SMS reminders for adherence. In addition, they should not have been planning to move out of Kadoma permanently during the study period and gave written informed consent to participant in the study. Those below 18 years and the severely sick were excluded.

\section{Intervention}

In the intervention group, participants received a motivational SMS reminder on a weekly basis for the duration of the trial. This was in addition to the standard HIV care afforded to clients. Messages were developed from message preference data collected at baseline. The message had a motivational and a reminder component. The message also included a phone number on which the client could raise any issues to do with treatment. The message content varied from week to week and was contemporary. An example of a message would be: "We are there for you; please remember to take your medication for any concerns contact $+263773 x x x x x x$." The messages made no mention of the words HIV or ART. In the non-intervention group, the participants received standard care as prescribed by the Zimbabwe ART guidelines. This comprised of CD4+ cell count, adherence classes, and, follow up (Ministry of Health. Zimbabwe 2016).

\section{Primary outcome}

The primary outcome was adherence to ART measured on a composite scale comprising of selfreported adherence, visual analogue scale (VAS), pill identification test (PIT) and pill counts. Participants were designated adherent to ART if they were considered adherent on all the four components. The method was piloted in South Africa (Steel G. et. al 2007).

\section{Secondary outcomes}

Secondary Outcome measures were weight, body mass index (BMI), CD4+ cell count, and viral load. The outcomes were measured at baseline and 26 weeks.

\section{Sample size}

The sample size calculated using Open Epi Version 3.03a ${ }^{\mathrm{TM}}$ was 306 assuming a 1:1 allocation ratio. The study had $80 \%$ power to yield a statistically significant result using a chi-squared test at alpha $=$ $0.05 / 2$. This calculation assumed a $10 \%$ improvement in 'adherence'over a baseline of $85 \%$ determined from the pilot by Muringazuva et.al (2015); rates which we felt were most representative of data available for Kadoma. Assuming attrition rates of approximately $10 \%$ we intended to enrol at least 332 participants for randomization.

\section{Randomization and allocation concealment}

A list of all clients in the RIHTC register who satisfied the inclusion criteria was compiled. The list was sequentially numbered by a data capture clerk. This was our sampling frame. A health information clerk generated random numbers using the Microsoft Excel $^{\mathrm{TM}}$ random number generator. The data 
capture clerk and the health information clerk handed over the sampling frame and the random numbers to the Clinic Manager. The Clinic Manager then compiled a list of the clients whose numbers on the ART registered corresponded with the randomly generated numbers. These were invited to participate in the trial. A recruiting nurse then did the group allocations. Allocation concealment among those who gave consent was done as described by Doig et. al. (2005).There was no restriction or blocking.

\section{Data collection and analysis}

Data were collected using a pretested interviewer administered questionnaire at baseline, and six months. Questionnaires were administered by data collectors who were fluent in the languages of the respondents. Adherence was assessed at each visit by enquiring about missed doses in the previous 30 days and calculating adherence according to pill counts. A weekly log was used to record the weekly SMS messages and any responses. A study register was kept for monitoring follow up.

The analysis and reporting of the results complied with the CONSORT, Consort e-health and SPIRIT 2013 guidelines (Gunther Eysenbach.2011 and Chan An-Wen 2013). The process of patient selection and flow throughout the study was summarized using a flow-diagram. The intention-to-treat principle was used to analyse all outcomes (Lewis' J.A. \& Machin D. I (1993) \& Montori V and Gordon H. Guyatt: 1993). We used the t-test for comparing groups on continuous outcomes and the chi-squared test for binary outcomes. All statistical tests were performed using two-sided tests at the 0.05 level of significance.

\section{Ethical considerations}

Written informed consent was obtained from all participants. The protocol was registered by the South African Medical Research Council (PACT20161001858240). Participants were free to withdraw from the study at anytime.

\section{Results}

\section{Consort diagram}

Five hundred and fifty-two (552) respondents were assessed on their eligibility to participant in the study. Five hundred and twelve (92.7\%) among those assessed owned a cell phone. Sixteen (3.06\%) intended to move out of Kadoma. The consort diagram is presented in figure 1.

\section{Demographic characteristics of respondents}

Whilst we assessed 522 potential respondents for the study, analysis was done on 449 respondents. Among these $320(71.27 \%)$ were females and $129(28.73 \%)$ were males. The median age of the respondents was 43 years $\left(\mathrm{Q}_{1}=36: \mathrm{Q}_{3}=49\right)$. The median number of months since HIV diagnosis was 59 $\left(\mathrm{Q}_{1}=34: \mathrm{Q}_{3}=87\right)$. The median number of months on since ART initiation to baseline study was 45 $\left(Q_{1}=29: Q_{3}=72\right)$. The demographic characteristics of the respondents stratified by the intervention arm are presented in table 1 . The only variable in which there was a significant difference in the proportions among those in the non-intervention and intervention groups was being married $(p=0.0001)$.

\section{Patterns of cell phone usage}

Among the 449 (100\%) respondents for which analysis was done, 415 (93.63\%) could read or send an SMS. The preferred method of communication on a cell phone was text 333(75.17\%), followed by voice $82(18.51 \%)$. The preferred language for SMS communication was Shona 310 (72.09\%), followed by English 115 (26.79\%). Eighty-two (18.47\%) of the respondents reported losing or having the phone damaged 12 months prior to the study. During the study $52(11.76 \%)$, reported losing or having phone damaged. The median duration without a handset was 4 weeks $\left(\mathrm{Q}_{1}=2: \mathrm{Q}_{3}=8\right)$. Four hundred and thirtyfour respondents $(97.75 \%)$ thought a text message could be useful for improving adherence to ART. However, $430(97.07 \%)$ were willing to be reminded by SMS to take ART medication. Cell phone usage patterns stratified by intervention arm are presented in table 2 .

There were no differences in the proportions of respondents across intervention arms on most of the variables we assessed on cell phone usage $(p>0.05)$. The only significant difference was noted in the proportions of respondents who indicated that a text message received on their phone was somewhat 
likely to be seen by others $(p=0.03)$. On the preferred message analysis none of the respondents preferred the word " $H I V$ " or " $A R T$ " to appear in the message. However, $196(43.65 \%)$ were comfortable with the word "medication" appearing in the message.

\section{Adherence rate by various measures}

At baseline 208 (96.74\%) among those in the non-intervention arm reported an adherence rate greater than $95 \%$ by self-report. This increased to $210(97.67 \%)$ after six months. Adherence measured by pill count had the lowest proportion of respondents with more than $95 \%$ adherence, $146(67.90 \%)$, at baseline and this proportion decreased to $138(65 \%)$ at the end of six months. Composite adherence measure had $131(60.93 \%)$ respondents being adherent, and this decreased to $127(59 \%)$ respondents at the end of 6 months. However, all these changes in proportion were not statistically significant $(p>0.05)$.

Among those in the intervention group, 223(95.37\%) of the respondents had more than 95\% adherence measured by the self-report method at baseline. Adherence measurement by pill count had the lowest proportion of respondents with more than 95\% adherence, at $159(67.90 \%)$ of the respondents. After six months the proportion of respondents in the intervention arm with more that $95 \%$ adherence by self-report was $229(97.96 \%)$ whilst the proportion of those with more than 95\% adherence by pill count had moved to $189(80.76 \%)$. All the changes in proportions were statistically significant $(p<0.05)$. The changes in adherence by various adherence measure in the experimental arms are presented in Table 3.

The proportion of respondents who were adherent by various measures stratified by intervention arm are presented in figure 2. At baseline there were no significant differences in the proportions of adherent respondents by self-report $(p=0.72)$, visual analogue scales $(p=0.71)$. However, there were significant different in the proportion of adherent respondents by pill identification test $(p=0.02)$. One hundred and thirty-nine $(59 \%)$ of the respondents in the intervention arm were adherent by composite measure compared to $131(60.93 \%)$ in the non-intervention arm. However, the difference in the proportions were not statistically significant $(p=0.65$ ).

After six months there were changes in proportions of respondents across intervention arms as measured by self-report $229(97.96 \%)$ in intervention arm and $210(96.74 \%)$ in the non-intervention $\operatorname{arm}(p=0.48)$. Significant differences across arms were noted in pill identification $(228 / 234 v s 164 / 215)$ $(p<0.05)$; pill count $(189 / 234 v s .138 / 215)(p<0.05)$ as well as the composite measure $(180 / 234 v s$ $127 / 215)(p=0.05)$. The changes in proportions of adherent clients at baseline and 6 months across intervention arms are presented in figure 3.

\section{Over adherence}

At baseline we found 39 (7.95\%) respondents with adherence rates above 100\%. Fourteen (35.89\%) were in the non-intervention group and 25 (64.10) we in the intervention group. The difference in the proportions was statistically significant $(p=0.01)$. At six months the number of respondents with above $100 \%$ adherence had decreased to $26(5.53 \%)$. Ten $(38.46 \%)$ were in the intervention arm and $16(61.53 \%)$ were in the non-intervention arms. However, the difference in the proportions was not statistical significant $(p=0.09)$

\section{Impact of SMS on health outcomes}

The changes in health outcomes among the respondents in the experimental arms are presented in table 4. Mean CD4+ cell count among those in the non-intervention group decreased from a mean of 593 cells per $\mathrm{mm}^{-3}$ at baseline to 554 cells per $\mathrm{mm}^{-3}$ at six months. The decrease was statistically significant $(p=0.002)$. Mean viral load also decreased from 4011 copies $^{m l^{-1}}$ to 2859 copies ml $^{-1}$. Viral suppression was reported by $93(43 \%)$ of the respondents in the non-intervention group. However, the decrease though good was not statistically significant $(p=0.25)$. There was however, a statistically significant decrease in the prevalence of opportunistic infections from $186(86.51 \%)$ prior to the study to $10(4.65 \%)$ during the six months we carried out the study $(p<0.05)$.

Among the respondents in the intervention group the mean CD4+ cell count was 556 cells per $\mathrm{mm}^{3}$ at base line and after six months intervention it increased to 619 cells per $\mathrm{mm}^{3}$. At baseline the means 
viral load was 8613 copies $m l^{-1}$ and it decreased to 392 copies $m l^{-1}$ at six months $(p=0.04)$. Viral suppression was reported by $140(60 \%)$ in the intervention group. The prevalence of opportunistic infections reported before the baseline study was 168 (71.79\%). During the six months intervention the prevalence of opportunistic infections was $6(2.56 \%)(p=0.00)$.

\section{Comparison of CD4+ cell counts at six months}

A comparison of CD4+ cells across the intervention arms at 6 months is presented as a box and whisker diagram in figure 4 . The means CD4+ cell count in the intervention arm at six months was 619 cells per $\mathrm{mm}^{3}$ whilst that in the non-intervention arm was 554 cells per $\mathrm{mm}^{3}(p=0.021)$.

\section{Comparison of weight changes}

The comparison of weight changes across intervention arms at baseline and at 6 months are presented in figure 5. The mean weight for those in the intervention arm increased from $63.01 \mathrm{~kg}$ to $65.66 \mathrm{~kg}$ and the increase was statistically significant $(\mathrm{p}=0.03)^{1}$. On the hand, among those in the non-intervention group the mean weight decreased from $64.32 \mathrm{~kg}$ to $62.40 \mathrm{~kg}$. However, the decrease was not statically significant ${ }^{2}$.

\section{Discussion}

This was a Health Centre based RCT study carried out during the period September 2016 through July 2017. The proportions respondents in the intervention arm and those in the non-intervention arm were distributed similarly across most demographic variables, therefore our respondents were comparable.

The proportion of adherent respondents measured on a composite scale significantly increased from baseline to outcome measurement after six months among those in the intervention arm. Notably, the proportion of adherent respondents decreased in the non-intervention arm during the same period. A decrease in the proportion of adherent respondents in the non-intervention group is not uncommon. Similar findings were reported by Pop- Eleches et. al. (2011) in a study carried out in Kenya. As the time on ART increases, patients start feeling better and with this comes treatment fatigue. This is when interventions such as reminders become important to encourage the patients to keep taking their medicines. Counselling to remind them that they are not cured and need to keep taking their medicines in the text messages is also important.

Of concern was that we found over adherent clients by pill count. Adherence rates above $100 \%$ are an indication that a client is taking more than the required doses at a time. Alternatively, this may indicate pill dumping. Sharing of medication may also lead to adherence rates above $100 \%$ by pill count. Such practise may lead to treatment failure (Reiter G., et.al. 2000 and Balogun M R, et. al.2012). Over adherence may also give results to side effects. If a client is taking more than the required dose, they are more likely to develop the signs of medicine toxicity which may threaten their lives. There is need for further investigation of this phenomenon and its effect on virological outcomes.

We found a higher cell phone ownership coverage of $92.72 \%$ among clients on ART at RIHTC. Comparable cell phone coverages were reported in studies carried out by Xiaoab et. al. (2013) in China (88\%), Kabede et. al. (2015) in Ethiopia (84\%), and Person et. al. (2011) in the USA-77\%. Most respondents in this study $333(75.17 \%)$ preferred text as routine communication; similar findings were reported Kabede et. al. (2015) who reported a text preference of $70 \%$. We found $369(82.18 \%)$ of the respondents, already using cell phones as reminders for medication. This is similar to $79 \%$ usage of cell phones as medicine reminders reported by Tamaryn et. al. (2010) in a study done in South Africa. Such high cell phone coverage presents a unique opportunity for communication with clients outside the health centre setting since health authorities would have ready means to communicate with their clients using cell phones. The high willingness of $97.07 \%$ among respondents to receive SMS medical reminders is an additional enabling factor.

Theft or damage to cell phones may derail any SMS interventions, in this study $97(18 \%)$ of respondents reported phone theft or damage in the 12 months preceding the study. This was lower than

\footnotetext{
1 Used Student T test.

2 Used Student T test.
} 
28\% reported by Tamaryn et. al. (2010) in South Africa and 51\% reported by Kabede et. al. (2015) in Ethiopia. We found that at six months; the proportion of respondents possessing a phone, changing cell phone numbers, losing or damaging to phones was similar across the experimental arms $(p>0.05)$. It therefore, follows that there was little or no impact on the intervention due to cell phone loss or theft.

We found sharing cell phones common, as such message send can be seen by non-target recipients. This calls for enhanced confidentiality in any SMS intervention. Confidentiality of the SMS reminder is important as some clients have internal stigma. If others see the message, it may result in acted stigma. All these are pertinent issues that HIV control programs should take into consideration at the design stage. Curioso et. al. (2009) in a study in Peru reported that keeping the medication reminders confidential was the most important concern that many clients on ART expressed. Respondents did not want revealing words like 'HIV', 'antiretroviral', or any other word related to HIV included in the SMS text. Respondents prefer messages that do not compromise confidentiality.

In the non-intervention group there were significant changes only in mean CD4+ cells count from baseline up to six months. There were no significant changes in mean BMI and viral loads. On the other hand, there were significant decreases in the viral load and increase in CD4+ cell count, as well as increase in BMI from among those in the intervention group at six months. This may be explained in part, by not only being on medication but adhering to the medication as well. This is consistent with the findings of Lester et. al. (2010) in the Weltel Study in Kenya. These findings further emphasise the need to give clients adequate support during their treatment.

We found that $140(60 \%)$ among those in the intervention group had viral suppression compared to $93(43 \%)$ in the non-intervention group $(p=0.004)$. A similar rate of suppression was reported by Lester et. al. (2010). Furthermore, we found a significant change in the weight among respondents in the intervention arm. Our result is similar to that reported by Mbuagbaw et. al. (2012) who also reported a significant change in weight among those in the intervention group compared to the control group.

Our study was not without limitations. Rimuka being a predominantly urban high-density area may have different social dynamics to low density areas and rural area. The spatial location may also influence the cell phone coverage. All these issues may limit the generalisability of the results. On the other hand, one may also argue that the high-density resident represents an average Zimbabwean in an urban setting. Another limitation may have been sharing or discussing the motivational messages by those in the intervention group with those in the non-intervention group. This is possible as respondents had opportunity to interact during clinics and support group meetings.

\section{Conclusion}

It is our conclusion that clients receiving care at Rimuka integrated TB and HIV centre are willing to be reminded to take their medication by means of a cell phone short message and the preferred language is predominantly Shona. However, the content of the message should not contain words like "HIV" or "ART" since the majority share their phones or leave the phones at places where they can be accessed by others.

Adherence among the clients seeking care at Rimuka was moderate based on the composite scale we used. Looking at individual measurement methods, most of the respondents were adherent based on the subjective measurement of the self-report. However, a more realistic measure of adherence was the use of the composite scale combining self-report, visual analogue scale, pill identification and pill count. We recommend that health authorities adopt such a composite scale as is sensitive enough to identify clients who may not be adherent compared to using one method only.

We further conclude that over adherence is a major issue that may threaten ART programs and this needs to be identified early where it occurs. Health authorities need to do hospital based and unannounced pill counts at households to identify and deal with this phenomenon.

Lastly, we conclude that the intervention (weekly motivational) short messages increased adherence (measured using a composite adherence scale) among respondents in this study. There were significant changes in the CD4+cells count, viral profiles. Respondents in the intervention group also had significantly high proportions of viral suppression compared to those in the non-intervention group. We therefore, recommend use of SMS, and, $m$ health in HIV care to improve health outcomes. 
DOI: $10.21522 /$ TIJCR.2014.05.01.Art003

ISSN: $2520-3096$

Notwithstanding the limitations, we believe this work has contributed to knowledge in that it has afformed that it is better to use a composite method in measuring adherence. Such a measure is more sensitive and can identify clients on ART who are likely to default, and, corrective measures and support could be availed earlier. It has also reaffirmed that weekly motivational short message texts improve adherence to medication and ultimately immunological and virological outcomes. However, large scale implementation of the intervention and its economies of scale need to be further investigated.

In the same vein, we recommend that further studies be done to determine the reproducibility and generalisation of these findings beyond Rimuka Integrated TB and HIV Care setting. We recommend that the intervention be tested in different areas like low-density and rural areas or areas with variability in socio demographic characteristics.

\section{Figures and tables}

Table 1. Socio demographics of respondents' kadoma mobile phone study (2016-17)

\begin{tabular}{|c|c|c|c|}
\hline Variable & $\begin{array}{l}\text { Intervention Group } \\
\mathrm{n}=\mathbf{2 3 4}(\mathbf{5 2 . 1 2 \%})\end{array}$ & $\begin{array}{l}\text { Non-Intervention } \\
\text { Group } n=215(47.88 \%)\end{array}$ & $p$-value \\
\hline Sex: Female & $166(70.94 \%)$ & $154(71.63 \%)$ & 0.87 \\
\hline Male & $68(29.06 \%)$ & $61(28.37 \%)$ & 0.87 \\
\hline Median Age (Years) & $44\left(Q_{1}=36: Q_{3}=50\right)$ & $42\left(\mathrm{Q}_{1}=36: \mathrm{Q}_{3}=48\right)$ & - \\
\hline Marital status: & $166(70.94 \%)$ & $115(53.74 \%)$ & 0.0001 \\
\hline \multicolumn{4}{|l|}{ Married } \\
\hline Divorces & $17(7.26 \%)$ & $22(10.28 \%)$ & 0.26 \\
\hline Separated & $14(5.98 \%)$ & $9(4.18 \%)$ & 0.38 \\
\hline Single & $15(6.41 \%)$ & $10(4.65 \%)$ & 0.42 \\
\hline Widowed & $72(30.77 \%)$ & $58(26.97 \%)$ & 0.37 \\
\hline Polygamous Union & $14(5.98 \%)$ & $8(3.72 \%)$ & 0.27 \\
\hline Religion: Apostolic & $57(24.35 \%)$ & $46(21.40 \%)$ & 0.45 \\
\hline Catholic & $35(14.95 \%)$ & $32(14.88 \%)$ & 0.98 \\
\hline Muslim & $8(3.41 \%)$ & $4(1.86 \%)$ & 0.31 \\
\hline None & $6(2.56 \%)$ & $12(5.58 \%)$ & 0.10 \\
\hline Pentecostal & $77(32.9 \%)$ & $81(37.67 \%)$ & 0.28 \\
\hline Protestant & $37(15.81 \%)$ & $32(14.88 \%)$ & 0.79 \\
\hline Traditional & $9(3.84 \%)$ & $7(3.26 \%)$ & 0.73 \\
\hline Other & $2(0.85 \%)$ & $1(0.47 \%)$ & 0.61 \\
\hline $\begin{array}{l}\text { Educational } \\
\text { attainment: None }\end{array}$ & $15(6.41 \%)$ & $6(2.70 \%)$ & 0.07 \\
\hline Primary Education & $49(20.94 \%)$ & $42(19.53 \%)$ & 0.71 \\
\hline Secondary & $166(70.94 \%)$ & $161(74.88 \%)$ & 0.35 \\
\hline \multicolumn{4}{|l|}{ Education } \\
\hline Tertiary Education & $4(1.71 \%)$ & $6(2.79 \%)$ & 0.44 \\
\hline Employment status: & $112(47.86 \%)$ & $85(39.53 \%)$ & 0.08 \\
\hline \multicolumn{4}{|l|}{ Unemployed } \\
\hline Formally Employed & $32(13.67 \%)$ & $40(18.60 \%)$ & 0.16 \\
\hline Self Employed & $90(38.46 \%)$ & $85(39.53 \%)$ & 0.81 \\
\hline $\begin{array}{l}\text { Median Hsehold } \\
\text { Income (US\$) }\end{array}$ & $80\left(\mathrm{Q}_{1}=40: \mathrm{Q}_{3}=150\right)$ & $100\left(Q_{1}=40: Q_{3}=200\right)$ & - \\
\hline $\begin{array}{l}\text { Median time since } \\
\text { diagnosis (mths) }\end{array}$ & $61.5\left(\mathrm{Q}_{1}=36: \mathrm{Q}_{3}=88\right)$ & $53\left(\mathrm{Q}_{1}=33: \mathrm{Q}_{3}=87\right)$ & - \\
\hline $\begin{array}{l}\text { Median duration on } \\
\text { ART(mths) }\end{array}$ & $47\left(Q_{1}=30: Q_{3}=75\right)$ & $41\left(Q_{1}=28: Q_{3}=72\right)$ & - \\
\hline $\begin{array}{l}\text { Who owns the house: } \\
\text { Council }\end{array}$ & $21(8.97 \%)$ & $17(7.90 \%)$ & 0.68 \\
\hline Owner & $62(26.49 \%)$ & $46(21.39 \%)$ & 0.21 \\
\hline Employer & $5(2.14 \%)$ & $6(2.79 \%)$ & 0.65 \\
\hline
\end{tabular}


Texila International Journal of Clinical Research

Volume 5, Issue 1, Jun 2018

\begin{tabular}{llll} 
Family & $69(29.48 \%)$ & $67(31.16 \%)$ & 0.69 \\
Private rented & $41(17.52 \%)$ & $37(17.20 \%)$ & 0.93 \\
Subtenant & $35(14.96 \%)$ & $38(17.67 \%)$ & 0.44 \\
Stays with Relatives & $31(13.25 \%)$ & $25(11.62 \%)$ & 0.60 \\
Stays with Parents & $16(6.84 \%)$ & $16(7.44 \%)$ & 0.80 \\
Stays with Children & $120(51.30 \%)$ & $118(54.88 \%)$ & 0.45 \\
Stays with Spouse & $104(44.44 \%)$ & $106(49.30 \%)$ & 0.30 \\
Stays with Alone & $30(12.82 \%)$ & $21(9.76 \%)$ & 0.30 \\
\hline
\end{tabular}

Table 2. Patterns of cell phone use-kadoma mobile phone study (2016-17) 2016

\begin{tabular}{|c|c|c|c|}
\hline Variable & $\begin{array}{l}\text { Intervention } \\
\text { Group } \\
(\mathbf{n}=\mathbf{2 3 4})\end{array}$ & $\begin{array}{l}\text { Non- } \\
\text { Intervention } \\
\text { Group } \\
(\mathrm{n}=\mathbf{2 1 5}) \\
\end{array}$ & $p$-value \\
\hline $\begin{array}{l}\text { Use Cell phone as medication } \\
\text { reminder }\end{array}$ & $194(82.90 \%)$ & $175(81.39 \%)$ & 0.67 \\
\hline SMS helpful in adherence to ART & $228(97.43 \%)$ & $206(95.81)$ & 0.33 \\
\hline $\begin{array}{l}\text { Willing to be reminded by SMS to } \\
\text { take medication. }\end{array}$ & $228(97.43 \%)$ & $202(93.95 \%)$ & 0.07 \\
\hline Preferred SMS language: English & $60(25.64 \%)$ & $55(25.58 \%)$ & 0.99 \\
\hline Shona & $165(70.51 \%)$ & $145(67.44 \%)$ & 0.48 \\
\hline Ndebele & $2(0.85 \%)$ & $2(0.93 \%)$ & 0.92 \\
\hline Chewa & $1(0.42 \%)$ & $0(0.00 \%)$ & 0.33 \\
\hline Have alternate number & $30(12.82 \%)$ & $48(22.32 \%)$ & 0.008 \\
\hline Preferred Communication: Voice & $42(17.9 \%)$ & $40(18.60 \%)$ & 0.86 \\
\hline WhatsApp & $15(6.41 \%)$ & $13(6.04 \%)$ & 0.87 \\
\hline Text & $175(74.78 \%)$ & $158(73.48 \%)$ & 0.76 \\
\hline Having phone with you: Always & $219(93.58 \%)$ & $206(95.81 \%)$ & 0.29 \\
\hline Seldom & $6(2.56 \%)$ & $1(0.46 \%)$ & 0.07 \\
\hline Sometimes & $7(2.99 \%)$ & $5(2.32 \%)$ & 0.65 \\
\hline $\begin{array}{l}\text { Cell phone damaged or lost in last } \\
12 \text { months }\end{array}$ & $42(17.94 \%)$ & $40(18.60 \%)$ & 0.85 \\
\hline Phone replaced with same number & $34(79.7 \%)$ & $36(90.00 \%)$ & 0.52 \\
\hline Switch off phone during day & $19(8.11 \%)$ & $22(10.23 \%)$ & 0.44 \\
\hline $\begin{array}{l}\text { Stores phone where others have } \\
\text { access }\end{array}$ & $167(71.36 \%)$ & $150(69.76 \%)$ & 0.71 \\
\hline Shares phones with others & $89(38.03 \%)$ & $81(37.67 \%)$ & 0.93 \\
\hline Phone has lock code /pattern & $37(15.81 \%)$ & $42(19.53 \%)$ & 0.30 \\
\hline Able to read or send text & $217(92.73 \%)$ & $198(92.09 \%)$ & 0.79 \\
\hline $\begin{array}{l}\text { Delete text deliberately without } \\
\text { reading }\end{array}$ & $18(7.69 \%)$ & $17(7.90 \%)$ & 0.93 \\
\hline $\begin{array}{l}\text { Text likely to be seen by others: } \\
\text { Somewhat likely }\end{array}$ & $18(7.69 \%)$ & $30(13.95 \%)$ & 0.03 \\
\hline Somewhat unlikely & $7(2.99 \%)$ & $3(1.39 \%)$ & 0.25 \\
\hline Very Likely & $140(59.82 \%)$ & $128(59.53 \%)$ & 0.95 \\
\hline Very Unlikely & $67(28,63 \%)$ & $51(23.72 \%)$ & 0.24 \\
\hline Use of internet on phone & $40(17.09 \%)$ & $40(18.60 \%)$ & 0.67 \\
\hline $\begin{array}{l}\text { Times do not answer unknown } \\
\text { calls }\end{array}$ & $71(30.34 \%)$ & $67(31.15 \%)$ & 0.85 \\
\hline \multicolumn{4}{|l|}{$\begin{array}{l}\text { Preferred Message Content } \\
\text { Analysis }\end{array}$} \\
\hline Reminder & $144(61.53 \%)$ & $118(54.88 \%)$ & 0.15 \\
\hline Remember & $20(8.54 \%)$ & $20(9.30 \%)$ & 0.78 \\
\hline
\end{tabular}


DOI: $10.21522 /$ TIJCR.2014.05.01.Art003

ISSN: $2520-3096$

Journey

$\begin{array}{lll}2(0.85 \%) & 2(0.93 \%) & 0.92 \\ 108(46.15 \%) & 88(40.93 \%) & 0.26 \\ 74(31.62 \%) & 74(34.42 \%) & 0.52 \\ 14(5.98 \%) & 6(2.79 \%) & 0.10 \\ 81(34.62 \%) & 82(38.14 \%) & 0.43 \\ 87(37.18 \%) & 91(42.33 \%) & 0.26 \\ 224 & 209(97.20 \%) & 0.39 \\ (95.72 \%) & & \\ 16(6.84 \%) & 9(4.18 \%) & 0.22 \\ 30(12.82 \%) & 22(10.23 \%) & 0.39 \\ & & \\ 23(9.82 \%) & 20(9.30 \%) & 0.85 \\ 220 & 196(91.16 \%) & 0.24 \\ (94.01 \%) & & \end{array}$

Table 3. Proportion of adherent respondents by adherence measure and experimental arm-kadoma mobile phone study (2016-17)

\begin{tabular}{|c|c|c|c|c|c|c|}
\hline \multirow{2}{*}{$\begin{array}{l}\text { Adherence } \\
\text { Measure }\end{array}$} & \multicolumn{3}{|c|}{ Non- Intervention Group $(\mathrm{n}=\mathbf{2 1 5})$} & \multicolumn{3}{|c|}{ Intervention Group $(\mathrm{n}=\mathbf{2 3 4})$} \\
\hline & Baseline & 6 Months & $p$-value & Baseline & 6 Months & $p$-value \\
\hline Self-Report & $\begin{array}{l}208 \\
(96.74 \%)\end{array}$ & $\begin{array}{l}210 \\
(97.67 \%)\end{array}$ & 0.55 & $\begin{array}{l}223 \\
(95.37 \%)\end{array}$ & $229(97.96 \%)$ & 0.19 \\
\hline VAS & $\begin{array}{l}201 \\
(93.45 \%)\end{array}$ & $\begin{array}{l}204 \\
(94.88 \%)\end{array}$ & 0.54 & $234(100 \%)$ & $218(93.47 \%)$ & 0.00 \\
\hline PIT & $\begin{array}{l}165(77.12) \\
146(67.90\end{array}$ & $\begin{array}{l}164 \\
(76.54 \%)\end{array}$ & 0.91 & $\begin{array}{l}197 \\
(84.18 \%)\end{array}$ & $228(97.52)$ & 0.00 \\
\hline Pill Count & $\%)$ & $138(65 \%)$ & & $159(67.9 \%)$ & $189(80.76 \%)$ & \\
\hline $\begin{array}{l}\text { Composite } \\
\text { Measure }\end{array}$ & $\begin{array}{l}131 \\
(60.93 \%)\end{array}$ & $127(59 \%)$ & 0.67 & $\begin{array}{l}135 \\
(57.69 \%)\end{array}$ & $180(76.92 \%)$ & 0.00 \\
\hline
\end{tabular}

Table 4. Virological indices by intervention arm- kadoma mobile phone study (2016-17)

\begin{tabular}{|c|c|c|c|c|c|c|}
\hline \multirow[t]{2}{*}{ Indices } & \multicolumn{3}{|c|}{ Non- Intervention $(n=215)$} & \multicolumn{3}{|c|}{ Intervention Group $(n=234)$} \\
\hline & Baseline & $\begin{array}{l}6 \\
\text { Months }\end{array}$ & $\begin{array}{l}p \text { - } \\
\text { value }\end{array}$ & Baseline & 6Months & $p$-value \\
\hline $\begin{array}{l}\text { Mean CD4+ (per } \\
\left.\mathrm{mm}^{-3}\right)\end{array}$ & 593 & 554 & 0.002 & 556 & 619 & 0.0001 \\
\hline $\begin{array}{l}\text { Mean Viral Load } \\
\left(\text { copies } m^{-1}\right)\end{array}$ & 4011 & 2859 & 0.25 & 8613 & 392 & 0.04 \\
\hline $\mathrm{BMI}\left(\mathrm{kg} / \mathrm{m}^{2}\right)$ & 23.63 & 24.60 & 0.84 & 23.55 & 24.37 & 0.001 \\
\hline $\begin{array}{l}\text { Prevalence of } \\
\text { Opportunistic }\end{array}$ & $186(86.51 \%)$ & $\begin{array}{l}10 \\
(4.65 \%)\end{array}$ & 0.00 & $\begin{array}{l}168 \\
(71.79 \%)\end{array}$ & $6(2.56 \%)$ & 0.00 \\
\hline $\begin{array}{l}\text { Infections (per } \\
\text { cent) }\end{array}$ & & & & & & \\
\hline
\end{tabular}


Texila International Journal of Clinical Research

Volume 5, Issue 1, Jun 2018

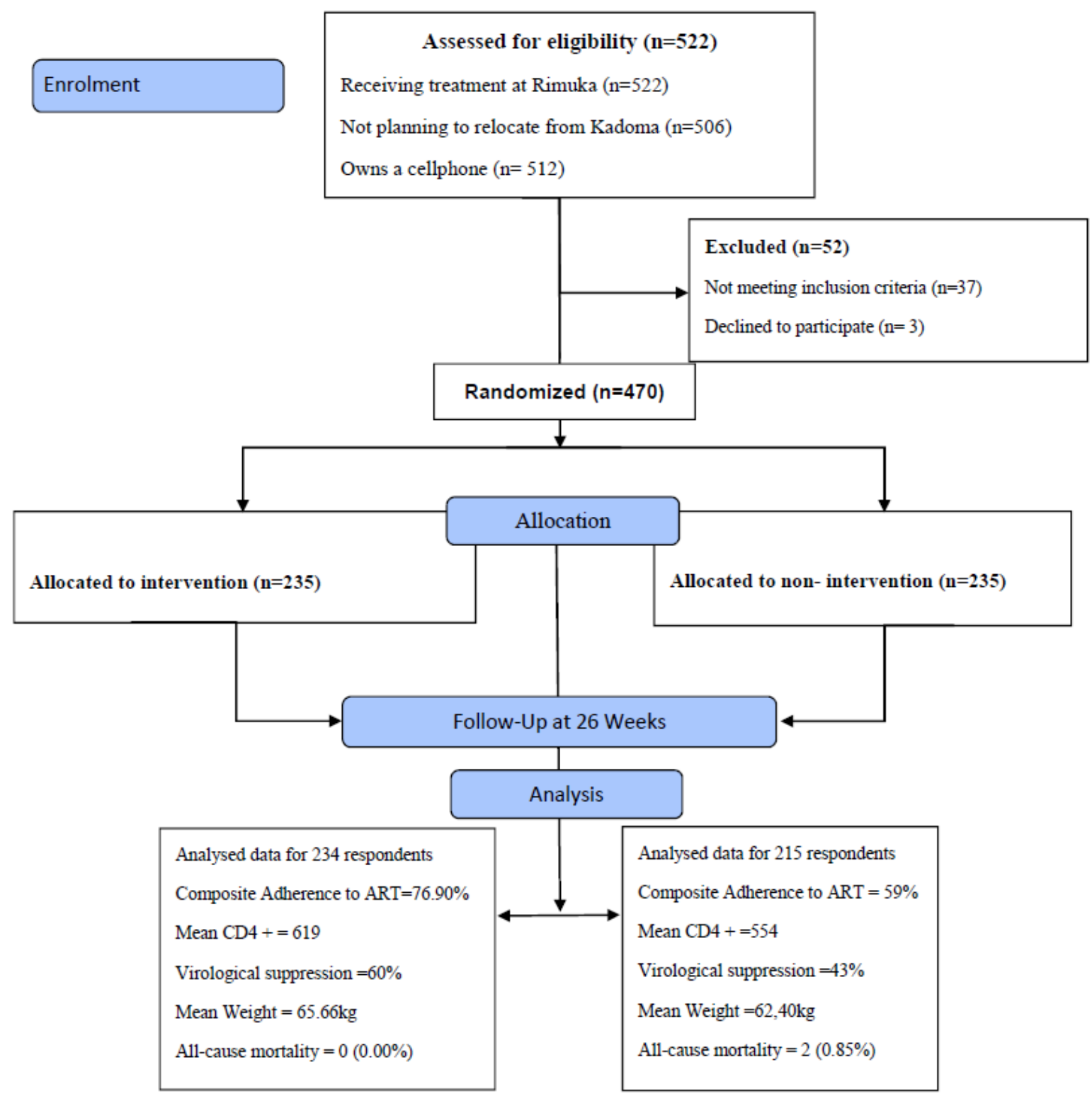

Figure 1. Kamps consort diagram 2016 
DOI: $10.21522 /$ TIJCR.2014.05.01.Art003

ISSN: $2520-3096$

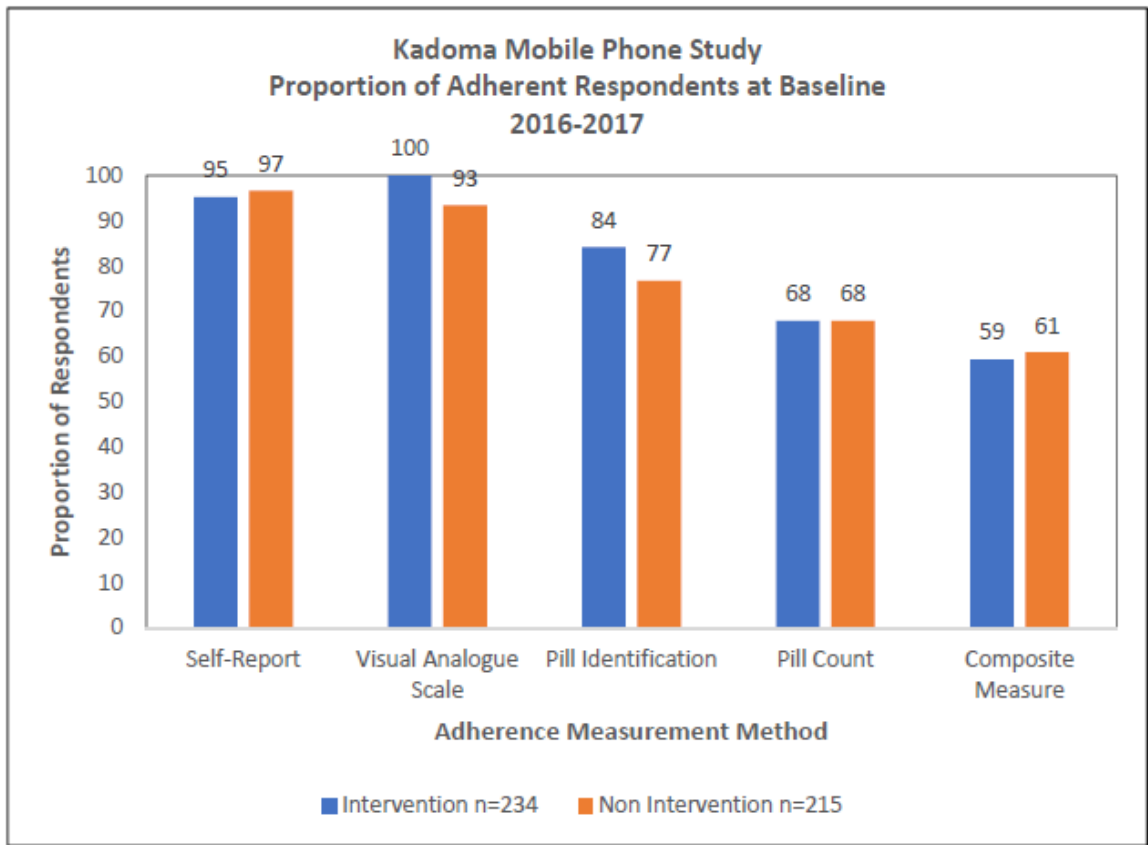

Figure 2. Proportion of respondent's adherence by various adherence methods at baseline

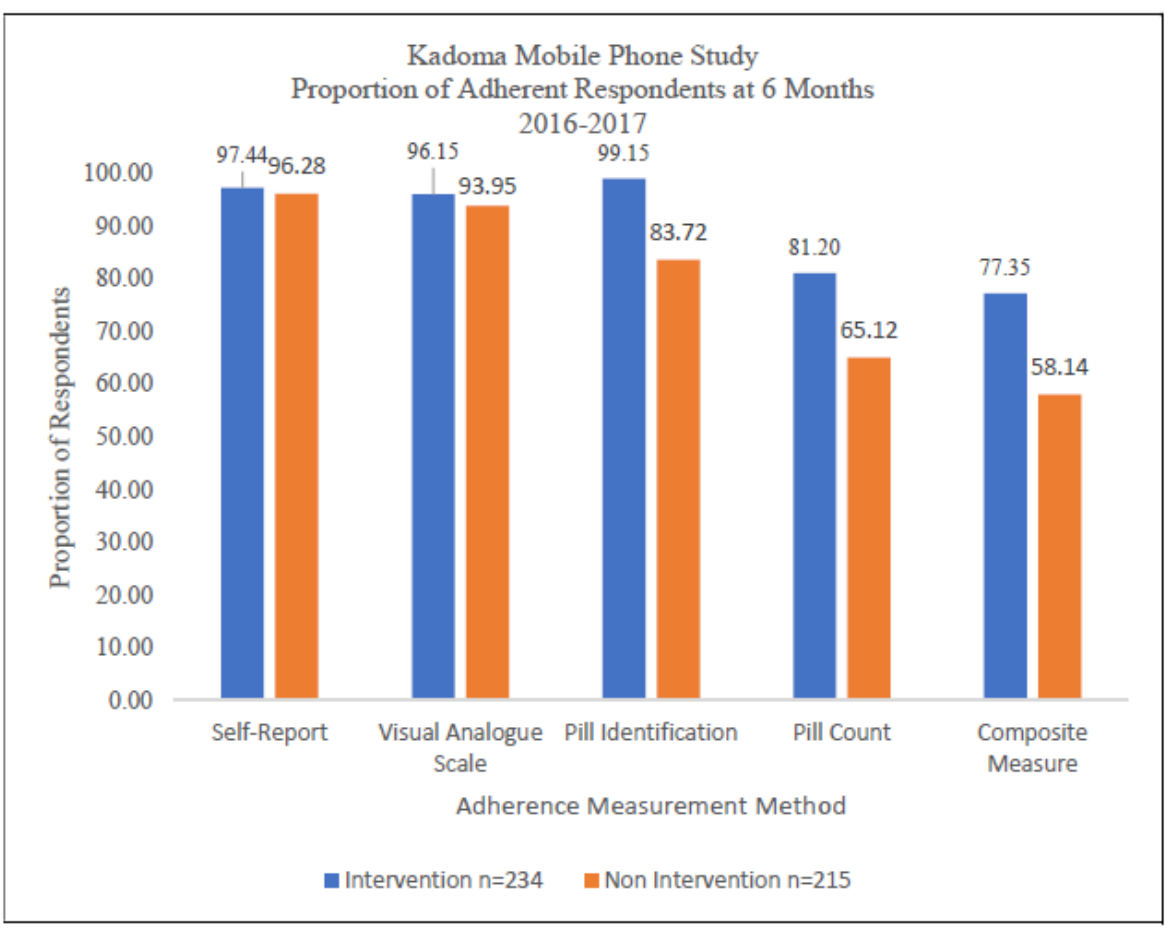

Figure 3. Proportion of adherent respondents by various adherence methods at 6 months 


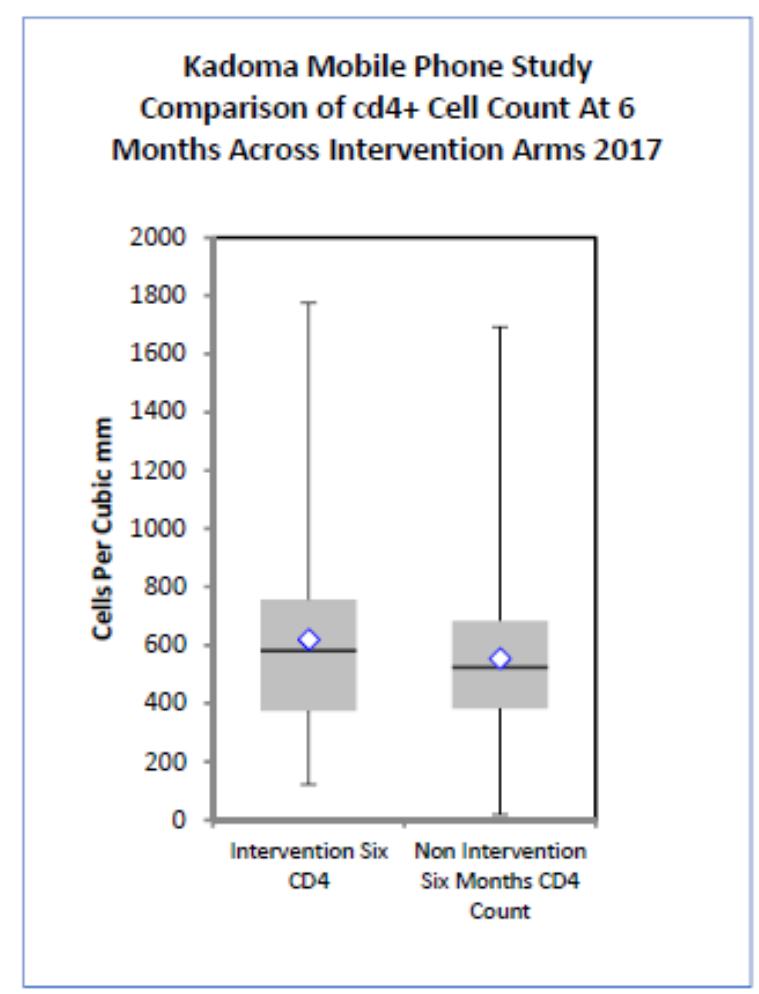

Figure 4. Comparison of CD4+ Cells at six months across intervention arms-kadoma mobile phone study (2016-17)

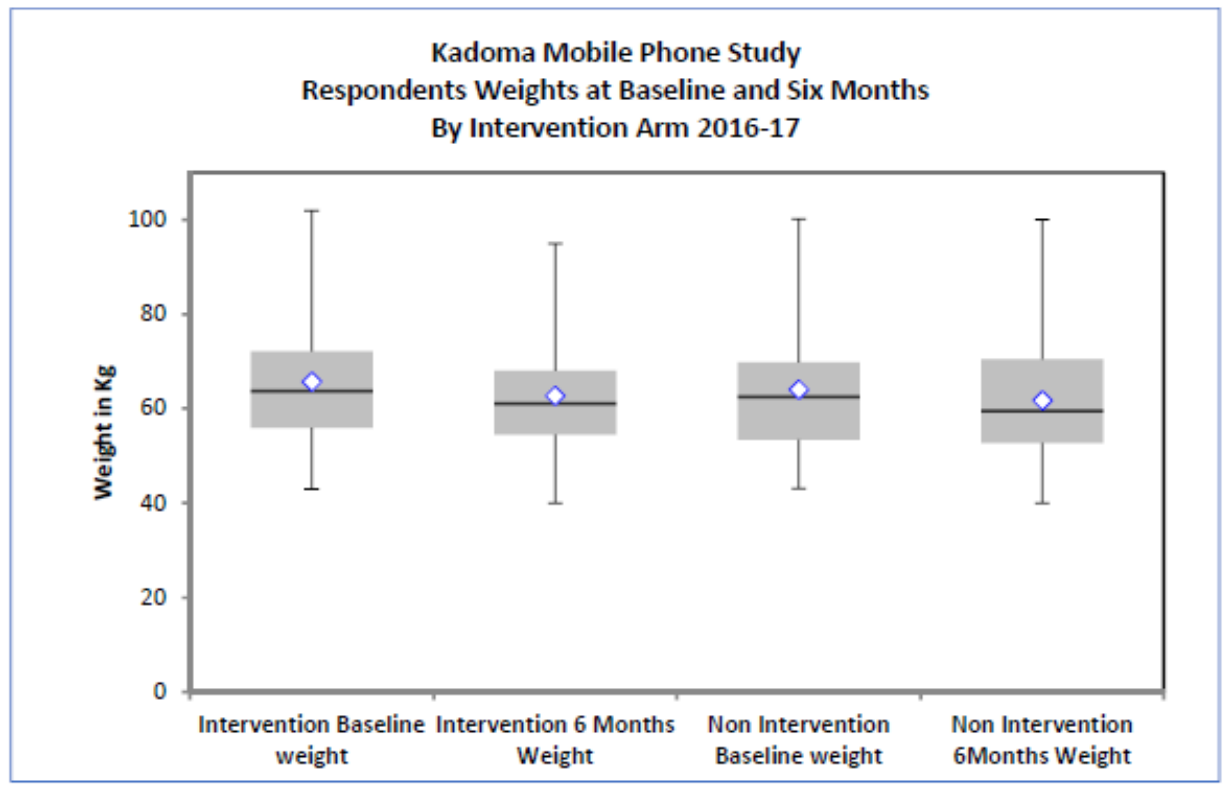

Figure 5. Comparison of respondents weights at baseline and six months

By Intervention Arm Kadoma Mobile Phone Study (2016-17)

\section{Acknowledgements}

This work was supported financially by Kadoma City Health Department. I wish to acknowledge the KAMP study team includes Gift Scholtz, Stella Manyere, Moffat Habibu, Alfred Maruma, Cecilia Suga, Blessing Banda, Precious Banda, Victoria Shongwe, Obert Chingosho Hamilton Gomba, Pamela Mautsa and Edith Mhike. Bongani Mkonto Matindife, Chamunorwa Mhende and Tendai Chipendo proof read the manuscript. 
DOI: $10.21522 /$ TIJCR.2014.05.01.Art003

ISSN: $2520-3096$

\section{References}

[1].Balogun M R, et. al. Access to information technology and willingness to receive text message reminders for childhood immunization among mothers attending a tertiary facility in Lagos, Nigeria. South Afr J Child Health. 2012.

[2].Bangsberg D. Less than $95 \%$ adherence to non-nucleoside reverse transcriptase inhibitor therapy can lead to viral suppression. Clin Infec Dis, 43(7):939-41. (2006)

[3].Braitstein P, Mortality of HIV-1-infected patients in the first year of antiretroviral therapy: comparison between low-income and high-income countries. Lancet;367(9513):817-24.). (2006).

[4].Chan An-Wen, SPIRIT Statement: Defining Standard Protocol Items for Clinical Trials: Ann Intern Med. 2013;158:200-207.

[5].Chan An-Wen: SPIRIT Explanation and Elaboration: Guidance for protocols of clinical trials: BMJ Research Methods and Reporting 31/01/2013 10:33:37.).

[6].Chirundu, S. et.al. Do Short Message Reminders Improve ART Adherence? Randomized Control Trial among HIV Clients - Kadoma (Zimbabwe) - KAMP Study Protocol., Texila International Journal of Clinical Research Voll Issue 1 June 2017)

[7].Curioso Walter H., et. al. "It's time for your life": How should we remind patients to take medicines using short text messages? AMIA 2009 Symposium Proceedings.

[8].da Costa, et. al. Results of a randomized controlled trial to assess the effects of a mobile SMS-based intervention on treatment adherence in HIV/ AIDS-infected Brazilian women and impressions and satisfaction with respect to incoming messages. Int $\mathbf{J}$ Med Inform. 2012 April; 81(4): 257-269 doi: 10.1016/j.ijmedinf.2011.10.002.

[9].Department of Health and Human Services. Guidelines for the use of antiretroviral agents in HIV-1-infected adults and adolescents. Available at http://www.aidsinfo.nih.gov/ContentFiles/AdultandAdolescentGL.pdf. Accessed 7 October 2017

[10]. Diederich W.E. \& Stenber H. The theory of Viral Infections; Topics in Medicinal Chemistry Springer 2015 DOI: $10.1007 / 978-3-662-46759-$

[11]. Doig Gordon S. and Fiona Simpson (2005): Randomization and allocation concealment: A practical guide for researchers.

[12]. Dongsheng H., et.al. Effects of a Phone Call Intervention to Promote Adherence to Antiretroviral Therapy and Quality of Life of HIV/AIDS Patients in Baoshan, China: A Randomized Controlled Trial. AIDS Research and Treatment Volume 2013, http://dx.doi.org/10.1155/2013/580974

[13]. Gunther Eysenbach. Consort-eHealth: Improving and Standardizing Evaluation Reports of Web-based and Mobile Health Interventions J Med Internet Res. 2011 Oct-Dec; 13(4): e126

[14]. Hammer S., et.al. A Controlled Trial of Two Nucleoside Analogue Plus Indinavir in Person with Human Immunodeficiency Virus Infection and CD4 Cell Counts of 200 per cubic Millimetre or Less. The New England Journal of Medicine Volume 337 Number 11) (1997).

[15]. Hardy et. al. Randomized Controlled Trial of a Personalized Cellular Phone Reminder System to Enhance Adherence to Antiretroviral Therapy; AIDS PATIENT CARE and STDs Volume 25, Number 3, 2011 DOI: 10.1089/apc.2010.0006.

[16]. Horne R, et.al. Concordance, adherence and compliance in medicine taking, National Co-ordinating Centre for NHS Service Delivery and Organisation R \& D. (2006)

[17]. Ickovics JR, \& Meade CS: Adherence to antiretroviral therapy among patients with HIV: a critical link between behavioral and biomedical sciences. J Acquir Immune Defic Syndr. Suppl 3: S98-102. (2002)

[18]. Kabede et. al. Text Messaging for Enhancement of Testing and Treatment for Tuberculosis, Human Immunodeficiency Virus, and Syphilis: A Survey of Attitudes Toward Cellular Phones and Healthcare; TELEMEDICINE and e-HEALTH APRIL 2011.94.

[19]. Kelly J. et.al. Text message reminders prior to the HIV clinic appointments do not improve retention in care when added to weekly text message reminders supporting adherence to ART in rural Sierra Leone -A randomised controlled - pilot study.

[20]. Labrique Alain B, et.al. mHealth innovations as health system strengthening tools: 12 common applications and a visual framework: Global Health: Science and Practice. Vol. 1 No.2 (2013).

[21]. Lima $\mathrm{V}$, et. al., Differential impact of adherence on long-term treatment response among naive HIV-infected individuals. AIDS, 22:2371-2380. (2008) 
[22]. Lester R. et.al. Effects of a mobile phone short message service on antiretroviral treatment adherence in Kenya (WelTel Kenya1): a randomised trial. The Lancet, Volume 376, Issue 9755, (2010).

[23]. Lewis' J.A. \& Machin D. Intention to treat - who should use ITT? Br. J. Cancer 1993 647-650.

[24]. Mbuagbaw L et.al. The Cameroon Mobile Phone SMS (CAMPS) triala randomized trial of text messaging versus usual care for adherence to antiretroviral therapy. PLoS One. 2012; 7(12): e46909. https://doi.org/10.1371/journal.pone.0046909:

[25]. Mills Edward J, et.al. Adherence to Antiretroviral Therapy in Sub- Saharan Africa and North America: A Meta-analysis. JAMA 296(6):679-690 (2006)

[26]. Ministry of Health. Zimbabwe Guidelines for Antiretroviral Therapy for the Prevention and Treatment of HIV in Zimbabwe Ministry of Health and Child Care, Harare (2016). Mocroft A, et.al. Decline in the AIDS and death rates in the EuroSIDA study: an observational study. Lancet. 362(9377):22-9. (2003).

[27]. Montori V and Gordon H. Guyatt: Intention-to-treat principle JAMC. 165. (10) (1993).

[28]. Muringazuva $\mathrm{C}$ et.al. Factors associated with Adherence to Anti-retroviral therapy among HIV clients, Kadoma city, Zimbabwe. Research Council of Zimbabwe (2015).

[29]. Palella FJ. et.al. Declining morbidity and mortality among patients with advanced human immunodeficiency virus infection. HIV Outpatient Study Investigators. N Engl J Med; 338:853-60) (1998).

[30]. Paterson David L., et.al. Adherence to Protease Inhibitor Therapy and Outcomes in Patients with HIV Infection. Ann Intern Med. 133:21-30. doi:10.7326/0003-4819-133-1-200007040-00004.

[31]. Person A.K., et. al. Text Messaging for Enhancement of Testing and Treatment for Tuberculosis, Human Immunodeficiency Virus, and Syphilis: A Survey of Attitudes Toward Cellular Phones and Healthcare; TELEMEDICINE and e-HEALTH APRIL 2011.94.

[32]. Pop-Eleches C. et.al. Mobile phone technologies improve adherence to antiretroviral treatment in a resourcelimited setting: a randomized controlled trial of text message reminders: AIDS; 25(6): 825-834. (2011) doi:10.1097/QAD.0b013e32834380c1.

[33]. Reiter G., et.al. Elements of success in HIV clinical care: Multiple interventions that promote adherence. Topics in HIV Medicine; 8:21-30. (2000)

[34]. Steel G., Nwokike J., Joshi M. Development of a Multi-Method Tool to Measure ART Adherence in Resource-Constrained Settings: The South Africa Experience. Submitted to the U.S. Agency for International Development by the Rational Pharmaceutical Management Plus Program. Arlington, VA: Management Sciences for Health. (2007).

[35]. Tamaryn C. et. al. Exploring the patterns of use and the feasibility of using cellular phones for clinic appointment reminders and adherence messages in an antiretroviral treatment clinic, Durban, South Africa. AIDS Patient Care STDS. 2010.

[36]. The PLATO Collaboration. Predictors of trend in CD4- positive T-cell count and mortality among HIV-1infected individuals with virological failure to all three antiretroviral-drug classes. Lancet; 364: 51-62). (2004). [37]. Xiaoab Y, et. al. Acceptability, and factors associated with willingness to receive short messages for improving antiretroviral therapy adherence in China. AIDS Care. (2013). 